\title{
Modalidad neoliberal
}

del Estado y gobierno

mexicano en sus procesos

de acumulación de

capital: ¿más Estado o

mercado?* / The

Neoliberal Mode of the

State and the Mexican

Government in its Processes

of Capital Accumulation:

More State or Market?

* Recibido: 17 de septiembre de 2013. Aceptado: 30 de octubre de 2013.

Tla-Melaua, revista de Ciencias Sociales. Facultad de Derecho y Ciencias Sociales. Benemérita Universidad Autónoma de Puebla, México / issn: 1870-6916 / Nueva Época, Año 8 No 36, Abril / Septiembre 2014, PP. 18-34. 


\section{RES UMEN}

Aunque la existencia del mercado no se limita al capitalismo y mucho menos al del siglo xx, coadyuva, como institución del Estado capitalista, en la reproducción de los procesos de acumulación de capital. Para ello es moldeada y reconfigurada. $\mathrm{Al}$ ser una relación social de compra y venta, el mercado es configurado y reconfigurado por los establecimientos tangibles (instituciones, derechos, reglas comerciales y fiscales) e intangibles (ideología) que el Estado y el gobierno imponen para fincar una sociedad en cada una de las dos modalidades (desarrollista o neoliberal) del capitalismo mexicano del siglo Xx.

El intervencionismo estatal y gubernamental, expresado en políticas de Estado y económicas de algún corte (desarrollista o neoliberal), se destina y materializa en la construcción y reconstrucción de los mercados. $\mathrm{Al}$ ser resultado de estas prácticas, el mercado no está en contradicción con el Estado capitalista. Sino más bien Estado y gobierno capitalista, mediante la construcción y reconstrucción de instituciones, incluyendo al mercado, garantizan la reproducción y acumulación de capital con la participación de los sujetos sociales (empresarios y trabajadores).

\section{PALABRAS CLAVE}

Estado capitalista, gobierno, modalidad, acumulación de capital, capital financiero, mercado.

\section{A B S TRACT}

Although the existence of the market is not limited to capitalism, much less the twentieth century, contributes, as an institution of the capitalist state through the reproduction process of accumulation of capital. For it is molded and reshaped. As one social relationship of buying and selling, the market is configured and reconfigured by tangible establishments (institutions, rights, trade and tax rules) and intangible (ideology) that the state and the government imposed to create a society in each of the two modalities (developmental or neo liberal) Mexican twentieth-century capitalism.

The state and government interventionism expressed in state policies and economic conditions of a certain line (developmental or neo liberal) and materialized in the construction and reconstruction of markets. As a result of these practices, the market is not in contradiction with the capitalistic state. Rather it is a state and a capitalist government, through the construction and reconstruction of institutions, including the market, guarantee the reproduction and accumulation of capital with the participation of social actors (employers and employees).

\section{KEYWORDS}

The capitalist state, government, mode, accumulation of capital, financial capital, market.

\footnotetext{
* Profesor investigador en la Facultad de Derecho y Ciencias Sociales de la Benemérita Universidad Autónoma de Puebla (BUAP), México. (samuel.amador@gmail.com)
} 

neoliberal: Estado-gobierno mexicano activo en la reconfiguración de la acumulación local de cara a las lógicas globalizadas del capital / 4. Conclusiones

\section{INTRODUCCIÓN}

El Estado capitalista manifiesta dos modalidades. Pensamos que no es claro hablar de un Estado propiamente keynesiano, desarrollista, de bienestar o neoliberal, pues en el fondo sigue siendo capitalista. Cabe entonces precisar que, aunque hablemos de un Estado capitalista a lo largo del siglo Xx y comienzos del xxi, han existido matices o modalidades estatales diferentes. Por tanto, es pertinente hablar de una modalidad del Estado capitalista que adquiere forma en políticas: keynesianas, desarrollistas, estructuralistas, benefactoras o neoliberales.

En el caso mexicano, Estado y gobierno capitalista, en su modalidad desarrollista, datan desde 1940 hasta principios de la década de 1980. Interviene como administrador y distribuidor de la riqueza mediante mecanismos como la estatización empresarial, que traslada ganancias garantizadas a la clase empresarial en consolidación mediante la fijación de precios de materias primas por debajo de los precios del mercado. En la modalidad neoliberal, esta situación se modificó, ya que el Estado-gobierno trasladó no sólo ganancias, sino activos y riqueza pública a manos de empresarios mediante los procesos de privatización realizados y dirigidos por él mismo.

Cabe precisar que no es el único mecanismo con el que cuenta el Estadogobierno para coadyuvar a los nuevos procesos de acumulación de capital por despojo. Los cambios establecidos en la modalidad neoliberal implicaron la construcción de un marco social, económico y político sujeto a transformaciones formales (jurídico, institucional) en las relaciones entre sus actores anteriores y nuevos. La acumulación capitalista en esta modalidad no sólo es una condición objetiva promovida y administrada por el Estado-gobierno, además involucra la participación organizada de personajes empresariales.

Ubicamos la modalidad neoliberal desde 1982, con la llegada de Miguel de la Madrid a la presidencia, hasta la actualidad. Desde entonces, la forma contemporánea de acumulación de capital dirigida desde el Estado-gobierno mexicano implicó que los derechos laborales y demás beneficios sociales, conseguidos por las clases trabajadoras, se vieran suplantados (burocrática o violentamente) por subvenciones públicas al capital de grupos de empresarios locales ligados al capital transnacional. 
Esto no significó que el Estado dejara de intervenir política y económicamente en los procesos de acumulación de capital. En esta modalidad su intervención económica se caracteriza por la construcción y definición de un tipo específico de mercado "libre". Para hacer que funcione la acumulación capitalista, el Estado-gobierno penetró (ideológica e institucionalmente) con mayor profundidad en segmentos de la vida política, social y económica, mediante mecanismos de mayor violencia (económica, física y simbólica).

En la actual modalidad neoliberal, el gobierno es conducido por un grupo de nuevos empresarios que forman la fracción hegemónica en el México contemporáneo, los cuales negocian en una posición política favorable de cara a los capitales internacionales (que en algún momento son competencia externa y en otro, comúnmente, grandes aliados). La bonanza de la acumulación capitalista en esta modalidad se basó en la capitalización de las relaciones/redes construidas con el poder político y la disposición o despojo de recursos y activos públicos que el Estado-gobierno (coludido) puso a su servicio. Estas contemporáneas formas de acumulación de capital no pueden entenderse sin la participación activa de organismos internacionales, entre los cuales destaca el Fondo Monetario Internacional (FMI).

\section{ORGANIZACIÓN EMPRESARIAL EN EL ESTADO MEXICANO Y LA MARAVILLOSA DÉCADA DE 1970}

Pensar que el Estado capitalista, por tener como objetivo garantizar las condiciones de producción y reproducción del capital, lo hará de manera automática, es asumir una visión reduccionista y restar importancia a la actividad (pública y privada) de los empresarios. Es decir, la realidad histórica muestra que los empresarios se organizan como actores colectivos, actúan constantemente para tener un peso significativo en la toma de decisiones de la función pública, de sus presupuestos y distribución de activos.

De acuerdo con un estudio realizado por Ricardo Tirado, ${ }^{1}$ la participación social del empresariado que influye en asuntos de índole pública y presupuestal puede catalogarse en tres formas: acción colectiva; derecho de picaporte; dirigiéndose a título individual y manera pública a la sociedad.

En México, las organizaciones empresariales ${ }^{2}$ surgen de un proceso lento que madura, aproximadamente, en la década de 1950, cuando las políticas de crecimiento e industrialización hacen necesario un polo especializado

\footnotetext{
${ }^{1}$ Tirado, Ricardo, "La visión del cambio de los grandes empresarios", en Ricardo Tirado (coord.), Los empresarios ante la Globalización, México D.F., Instituto de Investigaciones Sociales-Unam e Instituto de Investigaciones Legislativa-Cámara de Diputados del H. Congreso de la Unión, 1994, p. 136.

${ }^{2}$ Valdés Ugalde, Francisco, Autonomía y legitimidad: Los empresarios, la política y el Estado en México, México, Siglo XXI, 1997, p. 245.
} 
de actores empresariales. Los orígenes de esas organizaciones se remontan varias décadas atrás.

La acción colectiva de los empresarios mexicanos en el siglo xx en defensa de sus intereses data de la Revolución mexicana, ${ }^{3}$ cuando tuvieron la necesidad de enfrentar a las fuerzas sociales; posteriormente, de manera particular, participaron en la creación del nuevo Estado surgido de la Revolución. Podemos observar el desarrollo de dicha acción colectiva empresarial en los albores del siglo xx:

- En 1917 fue creada la Confederación de Cámaras de Comercio (Concanaco).

- En 1918 fundada la Confederación de Cámaras Industriales (Concamin).

- A tres años de creado el Banco de México (1925), se creó la Asociación de Banqueos de México.

- En 1929, fundada como sindicato patronal, surgió la Comisión Patronal de la República Mexicana (Coparmex).

- A un año de la llegada del presiente Manuel Ávila Camacho, en 1941, se creó la Cámara Nacional de la Industria de Transformación (Canacintra).

La aparición de las organizaciones empresariales no es fortuita. Está ligada al desarrollo de su actividad en las ramas industriales y el desarrollo del capitalismo mexicano. De acuerdo con Rogelio Hernández, ${ }^{4}$ en 1929 las actividades agropecuarias representaban 24\% del PIB, en tanto que las manufacturas solamente 12\%. Esta actividad comprendía las ramas más tradicionales, como los textiles, hierro y acero, cerveza, calzado y artículos de cuero, papel, cemento, tabaco, trigo y azúcar. Esta distribución cambió a partir del crecimiento económico del país en la década de 1940, producto de la aparición de ramas productivas que se convirtieron en la base de la industrialización sustitutiva de importaciones, bajo el apoyo y protección del gobierno mexicano.

De 1955 a 1980 se dieron dos cambios fundamentales en la estructura del empresariado mexicano. El primero, en la diferencia de tamaño de los establecimientos privados, que se transformó finalmente en capacidad económica desigual y en intereses no siempre compatibles, pese a pertenecer a la misma rama productiva. El segundo consistió en el fortalecimiento

\footnotetext{
${ }^{3}$ Puga, Cristina, "Las organizaciones empresariales en la negociación del TLC", en Ricardo Tirado (coord.), Los empresarios ante la Globalización, México D.F., Instituto de Investigaciones Sociales-Unam e Instituto de Investigaciones Legislativa- Cámara de Diputados del H. Congreso de la Unión, 1994, p. 174. ${ }^{4}$ Hernández, Rogelio R., "Problemas de representación en los organismos empresariales", en Cristina Puga y Ricardo Tirado (coords.), Los empresarios mexicanos, ayer y hoy, México, Caballito, 1992, pp. 249- 258.
} 
económico desde el Estado-gobierno mexicano de un puñado de grandes consorcios que se convirtieron en líderes de cada sector de actividad, gracias a la concentración del capital y al volumen y valor de la producción. Lo característico del segundo momento fue el predominio un grupo de consorcios líderes; las agrupaciones empresariales tomaron otra dimensión y rebasaron los límites representativos de los sectores económicos gremiales del pasado. ${ }^{5}$

En las décadas de 1960 y 1970 sucedieron dos eventos importantes que definieron el rumbo organizacional empresarial y marcaron la participación y agrupación de la fracción económica y política hegemónica de la próxima modalidad neoliberal: a) la creación del Consejo Mexicano de Hombres de Negocios (CMHN) y, b) el Consejo Coordinador Empresarial (CCE). Para ser precisos, en 1962 el sector privado de élite creo el CMHN como una estrategia de doce empresarios, encaminada a incidir en la política económica del gobierno de Adolfo López Mateos (1958-1964) y en la sucesión presidencial. Para 1975, el número de integrantes creció a treinta. ${ }^{6}$

El Consejo Coordinador Empresarial (CCE) fue fundado en 1975 como una organización de organizaciones integrada por siete principales organizaciones que "representan" (desde la tradición vertical) a todos los sectores empresariales del país: Concanaco, Concamin, Consejo Nacional Agropecuario (CNA), Asociación Mexicana de Instituciones de seguros (AMIS), Asociación Mexicana de Casas de Bolsa (АMCB), Consejo Mexicano de Hombres de Negocios (СMHN) y la Confederación Patronal de la República Mexicana (Coparmex).

La creación del CCE coincidió con un contexto en el cual el Estadogobierno mexicano se caracterizó por la creciente promoción de una economía altamente monopolizada, ${ }^{7}$ que incluye la actividad de empresas estatales y grupos privados nacionales en alianza con empresas extranjeras en los procesos de acumulación de capital. La concentración de activos públicos estatales (incluyendo el portentoso sector paraestatal) posibilito su entrega al grupo de poder económico y político hegemónico, mediante el mecanismo de la privatización y bajo el discurso ideológico del adelgazamiento del Estado en la modalidad neoliberal.

Observando los resultados ${ }^{8}$ de la década de 1970, podemos corroborar la reconfiguración que se dio en el grupo de poder económico:

\footnotetext{
${ }^{5}$ Puga, Cristina, "Las organizaciones empresariales en la negociación del TLC", en Ricardo Tirado (coord.), Los empresarios ante la Globalización, México D.F. Instituto de Investigaciones Sociales-unam e Instituto de Investigaciones Legislativa-Cámara de Diputados del H. Congreso de la Unión, 1994, p. 175.

${ }^{6}$ Basáñez, Miguel, La lucha por la hegemonía en México 1968-1990, México D.F., Siglo XXI, 1990, p. 96.

${ }^{7}$ Aguilar M., Alonso, Carmona, Fernando y Carrión, Jorge, Problemas del capitalismo mexicano, México, Nuestro Tiempo, 1976, p. 33.

${ }^{8}$ Morera Camacho, Carlos, El capital financiero en México y la globalización: Límites y contradicciones, México, Era, 1998, p. 38.
} 
a) $\mathrm{Al}$ iniciar la década, la concentración y centralización del capital ya era lo suficientemente grande, pues cuatro grupos financieros privados (Bancomer, Banamex, Serfín y Comermex) controlaban una buena cantidad de ramas productivas, que incluían a la industria ligera y a las más dinámicas, entre las que se encontraban la química, la petroquímica y la de fabricación de maquinaria.

b) Los déficits gubernamentales (impuestos netos $<$ gasto de gobierno) eran realmente grandes, ya que la forma recurrente de financiarlo fue la deuda pública externa, que creció 16.4 veces de 1971 a 1976: de 257 millones de dólares a 4216 millones de dólares.

c) En lo financiero, la creación de la banca múltiple en 1976 aceleró la integración de los grupos financieros bancarios nacionales, potenciando el vínculo de la esfera productiva con la financiera.

d) La petrolización de la economía permitió a los grandes grupos financieros el acceso a créditos externos, lo que facilitó la expansión en la inversión productiva y patrimonial, y en la especulación financiera.

En 1970, al comenzar9 el gobierno de Luis Echeverría, existieron unas mil familias que controlan buena parte de la riqueza nacional; para 1976, no eran más de quinientas, y constituían el eje de la oligarquía mexicana. Sus empresas, representadas en corporaciones, sumaban un grupo de treinta a cuarenta grupos financieros principales, que operaban de manera simultánea en las más variadas actividades económicas, y gozaban de un régimen de relaciones estrechas entre las empresas privadas, estatales, nacionales y extranjeras. Entre los grupos más poderosos y destacados de la oligarquía nacional en la década de 1970 se encuentra el grupo de Monterrey (con orígenes desde 1890), el grupo de Guadalajara y el grupo del Noreste.

En su libro El capital financiero en México y la globalización, Carlos Morera habla de una oligarquía financiera muy poderosa, constituida por veintiséis familias, hasta antes de la nacionalización de la banca. ${ }^{10} \mathrm{Su}$ perfil está incluido en uno de los cuatro tipos de inversionista en la propiedad accionaria de los grupos económicos a finales de la década de 1970. Los cuatro tipos de inversionista son: a) inversión directa de familias o sociedades de inversión familiares (oligarquía); b) inversión directa y a cuenta de terceros de los consorcios bancarios y financieros privados (como casas de bolsa, aseguradoras privadas, banca comercial y financieras privadas); c) propiedad del Estado y d) inversión extranjera directa por medio de trasnacionales o de bancos.

\footnotetext{
${ }^{9}$ Aguilar M., Alonso, Carmona, Fernando y Carrión, Jorge, Problemas del capitalismo mexicano, México, Nuestro Tiempo, 1976, p. 82.

${ }^{10}$ Morera Camacho, Carlos, El capital financiero en México y la globalización: Límites y contradicciones, México, Era, 1998, p. 104.
} 
Carlos Morera observa que, particularmente hasta antes de la nacionalización de la banca, la propiedad familiar de los grupos privados nacionales alcanzó su mayor expansión, desarrollo y fortalecimiento. También afirma que los grupos privados nacionales se expandieron a partir de una combinación importante en los sectores productivos y financieros. El orden de su participación en esta combinación sectorial es importante, pues marca la diferencia al interior de la oligarquía. De ello se desprenden dos situaciones: a) los grandes propietarios cuyo núcleo central era el sector productivo y que a la vez poseían consorcios bancarios-financieros, como visA, Vitro, Peñoles y Celulosa de Chihuahua, los cuales eran propietarios mayoritarios de Grupo Serfín, Banpaís, Cremi y Comermex, y b) los grupos cuyo núcleo central de acumulación se encontraba en el sector de servicios bancariosfinancieros, como Bancomer y Banamex, cuyos principales accionistas ejercían el control de manera centralizada, aunque la forma propiedad capitalista se encontraba socializada.

El apoyo que el gobierno de Echeverría y López Portillo brindó a la clase empresarial durante la década de 1970 se expresó en el rescate masivo de empresas privadas para su estatización y la permisividad de un sobreendeudamiento internacional privado para su posterior traslado a las cuentas públicas a través de la nacionalización de la banca, situación que decantó al final de cada sexenio presidencial en crisis económicas onerosas caracterizadas por un sobreendeudamiento público e inflación exorbitante.

Desde nuestra perspectiva, la extraordinaria estatización empresarial en tan sólo una década, producto del rescate de la iniciativa privada y la nacionalización de la banca, reconfiguró estos cuatro órdenes o formas de inversión. La agresiva o violenta insistencia del cambio de modalidad de acumulación se inscribe en la "solución" a la crisis de sobreacumulación que, a nivel mundial, explotó en la década de 1970. En México, y particularmente al final del sexenio de López Portillo, la crisis se mostró en los grupos económicos locales que aprovecharon como garantía la bonanza petrolera de este sexenio para sobreendeudarse con el exterior.

Al desatarse la crisis al fin del sexenio portillista, su situación financiera fue realmente grave, pues la deuda que contrajeron en dólares se multiplicó debido a la gran devaluación del peso. La consecuencia económica (para cualquier empresario) de este mal "cálculo" es la quiebra o muerte económica; sin embargo, este grupo asumió que los recursos (incluyendo la abundancia petrolera) con los que cuenta el Estado-gobierno estaban a su disposición ante cualquier eventualidad; efectivamente, así sucedió.

La nacionalización bancaria ejecutada por parte del Estado-gobierno de López Portillo les permitió a los grupos económico-financieros contar con dinero generado por la compra de sus bancos y pasar la factura de su crisis al conjunto social mexicano. Al salvarse de la debacle se reconfiguraron no 
sólo como grupo de poder económico, sino también como grupo hegemónico dirigente de la modalidad neoliberal, con la posterior predominancia del capital financiero-industrial. Por tanto, el agotamiento de la forma de acumulación predominante, por más de cuatro décadas, que con la nacionalización de la banca llegó a su fin, representó en el fondo un esfuerzo desde el Estado-gobierno por rescatar a los grupos económicos industriales, y financieros locales de la enorme catástrofe crediticia.

Al nacionalizarse la banca, el gobierno "concluye" formalmente ${ }^{11}$ con la división de funciones que existía desde varias décadas atrás entre los sectores público y privado en el ámbito financiero. El fin de la división de funciones entre los sectores público y privado en el sistema financiero fue de suma importancia para lo que vendría en la modalidad neoliberal, ya que dicha centralización pública del sistema financiero permitió sanearlo y perfilarlo para su posterior devolución al grupo de poder reconfigurado.

Ya en la modalidad neoliberal, su saneamiento y posterior devolución a la iniciativa privada (local e internacional), a partir de las medidas promovidas y tomadas por el presidente Miguel de la Madrid, reconfiguró no sólo los órdenes de inversión de lo industrial-financiero a lo financieroindustrial, sino también al grupo de poder económico y a la élite hegemónica Estado-empresarial. Es decir, la concentración pública de la banca en propiedad del Estado-gobierno mexicano y su postrera devolución se convirtió en un resorte importante para la acumulación de capital mexicano y extranjero. Destino semejante tuvo con su privatización el enorme aparato empresarial paraestatal.

\section{MOdALidAd NEOLIBERAL: ESTADO-GOBIERnO MEXICANO ACTIVO EN LA RECONFIGURACIÓN DE LA ACUMULACIÓN LOCAL DE CARA A LAS LÓGICAS GLOBALIZADAS DEL CAPITAL}

Inglaterra, Estados Unidos y Chile, durante la década de 1970, fueron los primeros países que implementaron el neoliberalismo; en el último caso, la imposición se dio bajo un golpe de Estado militar. Ya en la década de 1980, la implementación o imposición del neoliberalismo fue un hecho. Es hasta la década de 1970 cuando el neoliberalismo adquiere viabilidad económica, mas no política y social. El neoliberalismo se aplicó en la mayoría de los países con apoyo, colusión y beneficio de un segmento empresarial y de su gobierno a través de medidas de militarización.

\footnotetext{
${ }^{11}$ Las comillas son porque en realidad el sector privado financiero no desapareció. El gobierno de Miguel de la Madrid alimentó y permitió la existencia de una banca paralela (casas de bolsa, arrendadoras financieras, aseguradoras y sociedades de inversión) que funcionaron a la par de los bancos estatales nacionales.
} 
El Estado-gobierno local en el neoliberalismo, contrario a lo que comúnmente se argumentó, desempeña un papel de suma importancia para operar y dirigir el reparto de los recursos públicos y la riqueza de los países a empresas transnacionales y a un segmento de la burguesía nacional que, ya para ese momento, tuvo la suficiente fuerza para impulsar su política, la mayoría de las veces violentamente (golpes de Estado políticos y militares). ${ }^{12}$ En el reparto de la riqueza nacional de los países donde se implementó el neoliberalismo, la clase política tuvo su recompensa; en algunos casos, lograron acumular la suficiente riqueza para convertirse en políticos empresarios integrantes del fragmento hegemónico elitista de la clase política y empresarial local.

De manera simultánea, en la arena política y social, la violencia y el miedo impulsan a este modelo: crear la subjetividad que la vía correcta se encuentra en el neoliberalismo, quien se oponga a su proyecto civilizatorio será castigado por la ley. Esta violencia tiene múltiples expresiones sociales. La criminalización de los movimientos sociales implicó la devastación desde la función pública de sindicatos, organizaciones civiles, ni que decir de las organizaciones guerrilleras. Finalmente, de manera paradójica, los representantes gubernamentales de la modalidad neoliberal criminalizaron la pobreza que coadyuvaron a acrecentar.

Los aspectos económicos sociales que conforman el prisma de ajustes estructurales implementados por los Estados y gobiernos signados por la política económica neoliberal están básicamente asociados (según el índice de eficiencia de las políticas estructurales del Banco Interamericano de Desarrollo) a cinco áreas: política comercial, política tributaria, política financiera, privatizaciones y legislación laboral. Para efectos sintéticos, sólo consignaremos algunos aspectos asociados a la cuestión financiera y de privatizaciones que explican los elementos predominantes de la acumulación de capital. ${ }^{13}$

La historia del capitalismo del siglo xx muestra que en su modalidad neoliberal, aproximadamente desde 1974 hasta la actualidad, resalta la existencia previa y predominante del consorcio empresarial típico llamado holding. Éste se conforma como un combinado de empresas y un banco que centraliza todas las operaciones financieras relacionadas con ellas. De

\footnotetext{
${ }^{12}$ Para el caso particular de la violencia en México, Carlos Montemayor nos ofrece una explicación fresca, comprometida y de largo aliento sobre cómo el Estado mexicano operó y sigue operando antes y durante la modalidad neoliberal, en su libros: Rehacer la historia: análisis de los nuevos documentos del 2 de octubre de 1968 en Tlatelolco, México, Planeta, 2000, y La violencia de Estado en México: Antes y después de 1968, México, Debate, 2010.

${ }^{13}$ Desarrollo una explicación para la mayoría de estas áreas en el capítulo 3 del libro que está en imprenta Modalidad neoliberal del Estado mexicano en sus procesos de acumulación de capital: 1982-2006. Dos casos representativos de acumulación: Emilio Azcárraga Jean y Carlos Slim Helú. Primera Edición: marzo de 2013. México D.F. Ediciones Gernika, S.A.
} 
hecho, las grandes empresas productivas han abierto departamentos que les permiten tener una gran capacidad financiera; los bancos, por su parte, se han adueñado de una parte importante de la industria y casi todos ellos han creado divisiones industriales que les permiten operar y orientar el flujo de su inversión productiva y especulativa. En esta fase, de acuerdo con Van den Eynde, ${ }^{14}$ los bancos, desde su aplicación intensiva de informática, logran hacer pasar por sus bóvedas virtuales y reales flujos muy elevados de operaciones comerciales que oscilan por su tamaño desde grandes, medianas y pequeñísimas, mismas que incluyen, por ejemplo, la nómina del obrero, sus pensiones y seguros, sus recibos mensuales, sus compras a crédito a cualquier escala. Es decir, un océano que incluye las operaciones económicas entre el Estado y los particulares, como impuestos, cotizaciones, subsidios y becas.

La disposición de esos flujos de dinero, al servicio del actual sistema bancario, potencializa la relevancia de este segmento del ciclo y su posterior preponderancia en la lógica de la acumulación de capital en la etapa contemporánea. Esa condición presagia o comienza el predominio del capital financiero sobre el resto del ciclo del capital (industrial y comercial), y a su vez marca la pauta de reorganización de los grupos empresariales a niveles mundiales y locales. En otras palabras, las medidas implementadas por y para la modalidad neoliberal ponen en primer plano la dictadura del capital financiero, con beneficios colaterales para el resto del ciclo del capital.

A la luz de esta dinámica general del capital financiero, enmarcamos el desarrollo de la acumulación en la historia del capitalismo mexicano en su modalidad neoliberal, incluyendo la reconfiguración de los grupos de poder políticos y empresariales locales.

Tras la nacionalización bancaria, de acuerdo con Miguel Basáñez, ${ }^{15}$ el gobierno de Miguel de la Madrid, desde el mismo día de su toma de posesión, anunció la privatización de 34\% del capital de los bancos nacionalizados. En pocos meses, se completó y comenzó a ejecutar un generoso plan de indemnizaciones para los banqueros expropiados. A esta decisión le siguió otra, quizá más importante: la reprivatización de las empresas propiedad de los bancos, otorgando preferencias a los exbanqueros para adquirirlas. Entre tales empresas figuraban las casas de bolsa, las compañías de seguros y el resto de los denominados intermediarios financieros no bancarios. Sin embargo, todo esto aún no era suficiente. El gobierno federal delamadrista impulsó el crecimiento de las casas de bolsa, colocando, a través de ellas, volúmenes crecientes de valores gubernamentales.

El Banco de México participó de manera determinante en el proceso de recuperación de la confianza de los empresarios financieros. En búsqueda de

\footnotetext{
${ }^{14}$ Van den Eynde, A., Globalización, la dictadura mundial de 200 empresas, México, Uníos, 2001, p. 43.

${ }^{15}$ Basáñez, Miguel, La lucha por la hegemonía en México 1968-1990, México, Siglo XXI, 1990, p. 254.
} 
esa confianza, dicho organismo propició la triangulación del endeudamiento interno del gobierno federal, a favor de los intermediarios no bancarios, al limitar el acceso gubernamental, que en el pasado recurría al gobierno para allegarse de recursos internos: el encaje legal.

De manera contradictoria, ${ }^{16}$ si se considera que las tasas de encaje legal son más reducidas que las que se pagan en el mercado de capitales, el Banco de México alentó la emisión de certificados de la tesorería y otros valores gubernamentales de renta fija (pagafes, petrobonos, etcétera) que serían colocados precisamente a través de las casas de bolsa. Con este cambio fundamental, empezaron a fluir hacia el mercado de valores volúmenes cada vez mayores de capitales e inversionistas. Desde el Banco de México, se generó una banca paralela (integrada por casas de bolsa, arrendadoras financieras, aseguradoras y sociedades de inversión). Uno de los responsables de este proceso fue el entonces director (1982-1998) del Banco de México, economista y político mexicano, Miguel Mancera Aguayo, egresado del Instituto Tecnológico Autónomo del México (ITAM), quien también trabajó en el Banco de Comercio (hoy BBva Bancomer) de 1953 a 1955.

Mediante el Banco de México, el Estado-gobierno reforzó la estrategia de consolidar a los intermediarios financieros no bancarios, al promulgar una nueva legislación que, entre otras cosas, prohibía a los bancos poseer casas de bolsa. Así, el manejo del mercado bursátil quedó en manos exclusivamente privadas. Dicha legislación limitó un monto anual, prefijado por el Banco de México, para conceder financiamiento al gobierno federal. De esta manera quedaba institucionalizada la intermediación privada del financiamiento interno del sector público. Los bancos tenían prohibido manejar por sí mismos la intermediación de sus sociedades de inversión de renta fija. $\mathrm{Al}$ piso de remates de la Bolsa Mexicana de Valores sólo tendrían acceso las casas de bolsa, cuyos agentes serían los únicos habilitados para comprar o vender acciones y valores bursátiles. Esto último refleja cómo, desde los cambios legales en el sistema financiero mexicano de esta época, se impulsó y benefició con normatividades e información privilegiada a miembros de la élite financiera nacional neoliberal.

Desde julio de 1985, el gobierno decretó un congelamiento casi total de crédito bancario. En la práctica, canceló temporalmente la tradicional función de intermediarios entre el ahorro y la inversión de los bancos. Las empresas comenzaron a ver al mercado bursátil como alternativa para la obtención de financiamiento, lo que reforzó el papel de los intermediarios financieros no bancarios, cuyos dueños adquirirían posteriormente los bancos durante la privatización, con Carlos Salinas.

${ }^{16}$ Ibid., p. 255. 
Estos cambios en la legislación financiera, promovidos por el Estadogobierno y ejecutados por el Banco Central, abonaron el terreno para una reproducción de la acumulación originaria en el sistema financiero, al mismo tiempo que proyectaron la próxima devolución de los bancos estatizados a nuevos empresarios financieros.

El sexenio de Miguel de la Madrid sirvió para que, cinco años después de la nacionalización de la banca, se consolidara una sólida e influyente fracción financiera de la clase dominante en el país. Con este precedente, no sería difícil para Carlos Salinas de Gortari continuar con la obra que consistía en la entrega completa del sistema financiero (dieciocho bancos estatales privatizados en un año) a la élite ya ubicada en esta área.

La política de "liberalización" financiera y la privatización de empresas estatales ejecutadas por el Estado mexicano van de la mano a través de la información que el sistema financiero permite a sus integrantes o a la banca paralela. Sólo durante el sexenio de Miguel de la Madrid, el número de entidades paraestatales, formado por 1155, se redujo 64.3\%. ${ }^{17}$ Cabe destacar que el periodo presidencial en el que se privatizaron las mejores empresas con un activo grande y poder de mercado importante fue el de Carlos Salinas de Gortari. Ello explica la fuerte concentración y centralización del capital como uno de los rasgos más destacados de su sexenio. ${ }^{18}$

De acuerdo con Enrique Cárdenas, ${ }^{19}$ de los 61600 millones de pesos obtenidos por la venta de 409 empresas paraestatales durante el sexenio salinista, 37800 millones de pesos provinieron de la venta de bancos: 61.36\% de los ingresos de la venta de las 409 empresas fue ingresado por sólo dieciocho de ellas.

Con el antecedente de las sucesivas crisis económicas que, entre otros efectos, llevaba a la falta de liquidez del sistema bancario, y tras el anuncio de la desincorporación de las instituciones de crédito, el gobierno de Carlos Salinas de Gortari instituye en 1990 el Fondo Bancario de Protección al Ahorro (Fobaproa), un fondo de contingencia para enfrentar problemas financieros extraordinarios, como la insolvencia de los bancos por el incumplimiento de los deudores con la banca y el retiro masivo de depósitos. Así, el Fobaproa serviría para asumir las carteras vencidas y capitalizar a las instituciones financieras.

La ayuda del Estado gubernamental, después de la crisis de 1982, no sólo consistió en la permisividad y apoyo de la banca paralela y la privatización

\footnotetext{
${ }^{17}$ Casar, María Amparo y Wilson Peres, El Estado empresario en México: ¿agotamiento o renovación?, México, Siglo XXI, 1988, p. 182.

${ }^{18}$ Información detallada sobre los personajes que se beneficiaron de la privatización sexenal salinista se encuentra en el libro Operación Telmex. Contacto con el poder, del periodista Rodríguez Castañeda.

${ }^{19}$ Cárdenas, Enrique, La política económica en México, 1950-1994, México, Fondo de Cultura Económica y El Colegio de México, 1996, p. 170.
} 
de empresas estatales, sino también en la política de rescate expresada en varios programas. La crisis de 1982 puso en situación de quiebra a los empresarios locales que aprovecharon el auge petrolero para endeudarse y capitalizar sus negocios. La quiebra fue transformada oportunamente en negocios en 1983, mediante el Fideicomiso para la Cobertura de Riesgos Cambiarios (Ficorca). Este fondo, dirigido por Ernesto Zedillo, utilizó recursos gubernamentales para salvar de la quiebra a veinte grandes empresas. El mecanismo fue asumir pasivos por 12000 millones de dólares mediante garantías del Banco de México. ${ }^{20}$ Este antecedente es de suma importancia pues, posteriormente, ya en su gobierno presidencial y con el mismo fin, Zedillo creó en 1996 la Unidad Coordinadora para el Acuerdo Bancario Empresarial (UCABE), que consistió en salvar a las más grandes e influyentes empresas deudoras. ${ }^{21}$

Las empresas beneficiadas por tal programa reestructuraron sus débitos, gracias a recursos fiscales a instancia de la Secretaría de Hacienda. El UCABE sirvió de aval para el rescate bancario y benefició a 54 empresas por un monto de 9700 millones de dólares. Al Igual que el Ficorca y el UcABE, el Fobaproa fue utilizado para el rescate de la elite empresarial; convirtió en deuda pública pasivos de dichos fondos que sirvieron para asistir a los bancos privados en crisis, cuyo monto ascendió a 552000 millones de dólares. Dicho monto equivale a 40\% del PIB de 1997, a las dos terceras partes del presupuesto de egresos para 1998 y el doble de la deuda pública interna. ${ }^{22}$

La constante "ayuda" financiera se conformó como el mecanismo de acumulación de capital que ejerció el grupo de poder económico y político sobre el erario, vía nacionalización, rescate o privatización que, finalmente, consiguieron pasar como deuda pública o justificarse en ella, situación que se ajustó al apoyo financiero del gobierno de Estados Unidos al gobierno mexicano. Lo que permitió pagar a deudores estadounidenses e incrementar la deuda con ese país. Deuda que el gobierno mexicano se ha encargado de ir pagando con los intereses adicionales ocasionados. Finalmente, el ciclo de la deuda organiza un gran negocio tanto para quien presta como para quien debe. Hay un tercero, que es el Estado-gobierno en su modalidad neoliberal, quien paga con recursos públicos, ${ }^{23}$ es decir, los costos de la

\footnotetext{
${ }^{20}$ Tomado de la página web de la Cámara de Diputados del Honorable Congreso de la Unión http://www.cddhcu.gob.mx/cronica57/contenido/cont2/fobaprol.htm, la cual refiere a la revista Proceso, 1131.

${ }^{21}$ López Obrador, Andrés Manuel, La mafia que se adueñó de México...y el 2012, México, Grijalbo, 2010, p. 27.

${ }_{22}^{2}$ Tomado de la página web de la Cámara de Diputados del Honorable Congreso de la Unión http:// www.cddhcu.gob.mx/cronica57/contenido/cont2/fobaprol.htm, la cual refiere a la revista Proceso, 1131. ${ }^{23}$ Situación que en la modalidad neoliberal ha sido una constante. Enrique Cárdenas hace una revisión de la deuda pública, privada y de la transferencia de recursos al exterior por concepto de pago de intereses; asegura que en el año de 1983 éstas llegaron a representar 12.3\% del PIB, cifra sin precedentes en la historia económica contemporánea del país.
} 
acumulación de capital por esa vía se socializan, castigando a la población en general.

Lejos de las expectativas generadas por el candidato del Partido de Acción Nacional (PAN) durante su campaña y a su llegada, después de 71 años de permanencia del PRI en el poder presidencial, el cambio de rumbo fue nulo, más bien mostró una profunda y reiterada aplicación. Paradójicamente, a pesar de la creciente concentración y centralización política y económica, la economía mexicana en su conjunto no fue capaz de absorber las necesidades de demanda de empleo y mucho menos de mejores salarios. Los datos relacionados con la reducción del poder adquisitivo del salario mínimo después de su máximo histórico en 1976 es una de las pruebas fehacientes de los costos sociales que su implementación derivo tras recurrentes crisis.

Al finalizar el sexenio presidencial de José López Portillo, el nivel del salario mínimo real había caído a 69.1\% del alcanzado en $1976 .{ }^{24}$ Con las reformas laborales promulgadas por la modalidad neoliberal en el primer sexenio que correspondió al presidente Miguel de la Madrid, el descenso al culminar su sexenio, en 1988, representaba ya 41.6\% del nivel de 1976, es decir, había descendido 30\%. En el sexenio siguiente, con el gobierno de Carlos Salinas de Gortari, la caída culminó con un nivel salarial equivalente a $31.2 \%$ del alcanzado en 1976, es decir, que durante su sexenio el salario cayó $10.4 \%$, en relación con el máximo histórico. Durante el sexenio de Ernesto Zedillo, la contracción relativa del salario fue de 22.78\%. Durante el foxismo, el salario mínimo real llegó a representar 23.98\% de lo que los mínimos registraron en su máximo histórico.

$\mathrm{El}$ ataque frontal contra los sindicatos independientes, contra la legislación laboral que contenía el contrato ley y la embestida por la reformulación de las leyes laborales ${ }^{25}$ son muestras accesorias consumadas hoy en su total previsión por parte del grupo hegemónico. No obstante, los resultados para ese grupo han sido alentadores, pues la contracción salarial ha mantenido su tendencia a la baja a niveles significativamente alarmantes; un elemento de

\footnotetext{
${ }^{24}$ La información para el cálculo se obtuvo de la Secretaría de Trabajo y Previsión Social (de 1976 a 1980) en http://www.conasami.gob.mx/pdf/salario_minimo/sal_min_gral_prom.pdf y de la Base de Estadísticas e Indicadores Sociales (Badeinso) de la CEPAL (de 1980 a 2006) en http://websie.eclac.cl/ sisgen/ConsultaIntegrada.asp?idIndicador $=340 \& i d i o m a=e$

${ }^{25} \mathrm{Al}$ respecto, Enrique de la Garza Toledo, un experto mexicano en estudios sobre trabajo, afirma, en su artículo "Reconversión industrial y cambio en el patrón de relaciones laborales en México" publicando en Anguiano A. (Coord.), La modernización de México, p. 335, que con el neoliberalismo se conforma un nuevo modelo contractual, diferente al de la Revolución mexicana, flexible, que implica la no intervención del sindicato en las decisiones e implementación de los cambios tecnológicos o de organización; el empleo, en parte, flexible de acuerdo a las necesidades de la producción (empleo irrestricto de subcontratistas o de trabajadores eventuales); uso flexible de los trabajadores dentro del proceso de trabajo (movilidad interna, polivalencias, escalafón no ciego, compactación de tabuladores); flexibilización salarial (aumento de la parte del salario correspondiente a los bonos por productividad individual) y salario por hora.
} 
su explicación puede ser la incorporación del trabajo femenino y de menores al mercado laboral. La composición familiar en la modalidad neoliberal implicó la cada vez más común integración de los ingresos por medio de remuneraciones al menos de tres integrantes.

\section{CONCLUSIONES}

La praxis del Estado capitalista a favor de la acumulación de capital no es algo nuevo; se manifiesta en diversas formas de intervención en todos los aspectos del conjunto social. Entre los instrumentos y acciones con los que cuenta el Estado capitalista para modificar al mercado institucionalizado podemos apuntar: el fisco, leyes para vender y comprar (lo legal y lo prohibido), las fronteras, cuotas-aranceles, "libertad" o fijación de precios, políticas laboral (flexible o no), subsidios o no, exenciones o no, fomento a la inversión (pública o privada) y gasto social, por citar algunos. Todo esto forma parte de un mercado institucionalizado producto del Estado capitalista, mediante sus políticas económicas y políticas públicas.

Por tanto, pensamos que hablar de un Estado interventor, en términos generales, es una ambigüedad. Porque habría que especificar en qué es o no interventor. Esto, si es que el Estado capitalista puede realmente llegar a tomar un posición de no intervención, incluso en la economía. El Estado capitalista en cualquier modalidad interviene de una forma u otra, siempre configurando o reconfigurando a las instituciones y, entre ellas, al mercado, con el fin de actualizarlas para el proceso de la acumulación de capital. La dicotomía simple de pensar y ver al Estado capitalista versus mercado representa una falacia.

El Estado en general y el gobierno en particular, para mantener vivos los procesos de acumulación de capital, intervienen con violencia, física o simbólica, política y económicamente. En el capitalismo del desastre, bautizada así la modalidad neoliberal de Estado capitalista por Naomi Klein, en su libro La doctrina del Shock, ${ }^{26}$ muestra cómo la supuesta libertad de mercados se respalda en acciones Estado-gubernamentales constantemente violentas en todo el mundo. El golpe de Estado militar y la posterior privatización del sistema de educación pública en Chile y en Nueva Orleans, después de Katrina, integran algunos de los ejemplos citados.

La administración Bush [que] empezó por subcontratar, sin ningún tipo de debate público, varias de las funciones más delicadas e intrínsecas del Estado [-gobierno]: desde la sanidad para los presos hasta las sesiones de interrogación de los detenidos, pasando por la

\footnotetext{
${ }^{26}$ Klein, Naomi, La doctrina del Shock: El auge del capitalismo del desastre, Barcelona, Paidós, 2007, pp. 26-34.
} 
«cosecha»y recopilación de información sobre los ciudadanos. El papel del gobierno en esta guerra sin fin [en Irak] ya no es el de un gestor que se ocupa de una red de contratistas, sino el de un inversor capitalista de recursos financieros sin límite que proporciona el capital inicial para la creación del complejo empresarial y después se convierte en el principal cliente de sus nuevos servicios. ${ }^{27}$

Estos son, entre otros, algunos ejemplos que caracterizan la nueva forma de intervención económica, política y social del Estado capitalista en los procesos de acumulación de capital. Las preguntas obligadas son: ¿De qué depende entonces el cambio de mercancías? ¿Cuáles son las condiciones en las cuales se da? ¿Cómo se modifican, crean o recrean en el mismo mercado? Los factores que median esas relaciones son múltiples: la evolución histórica del desarrollo del capitalismo a nivel mundial y local, la lucha de clases, la dominación, pugnas intraburguesas, entre otros aspectos, dan forma a una u otra modalidad del Estado capitalista.

El Estado capitalista lo es en cualquier fase de su desarrollo; se requiere aclarar que no existe propiamente un Estado keynesiano, estructuralista, desarrollista o neoliberal, sino una modalidad del mismo Estado capitalista que en cualquiera de ellas continúa siendo capitalista, es decir, creando y recreando el ya institucionalizado mercado con destino a la ininterrumpida ruta de acumulación de capital. La modalidad neoliberal en México no es la excepción y por lo tanto la "libertad de los mercados" está sustentada en una acción Estado gubernamental que implica la recreación de la institución mercado con costos sociales totalmente desgarradores.

De acuerdo con lo observado, en la antesala (década de 1970) y con más énfasis en la modalidad neoliberal (desde 1982 hasta la actualidad), las palancas de acumulación de la riqueza y capital en la reconfiguración del grupo de poder hegemónico económico y político fueron: la nacionalización de la banca, las deudas (Ficorca, UCABE, Fobaproa y rescates), las privatizaciones, la corrupción gubernamental, la evasión y devolución fiscal y el crimen organizado. Los medios para la acumulación: el Estado-gobierno, la política económica y las redes de poder político-empresarial. Las figuras de la acumulación: empresario, político empresario y empresario político.

\footnotetext{
${ }^{27}$ Ibid., p. 35.
} 


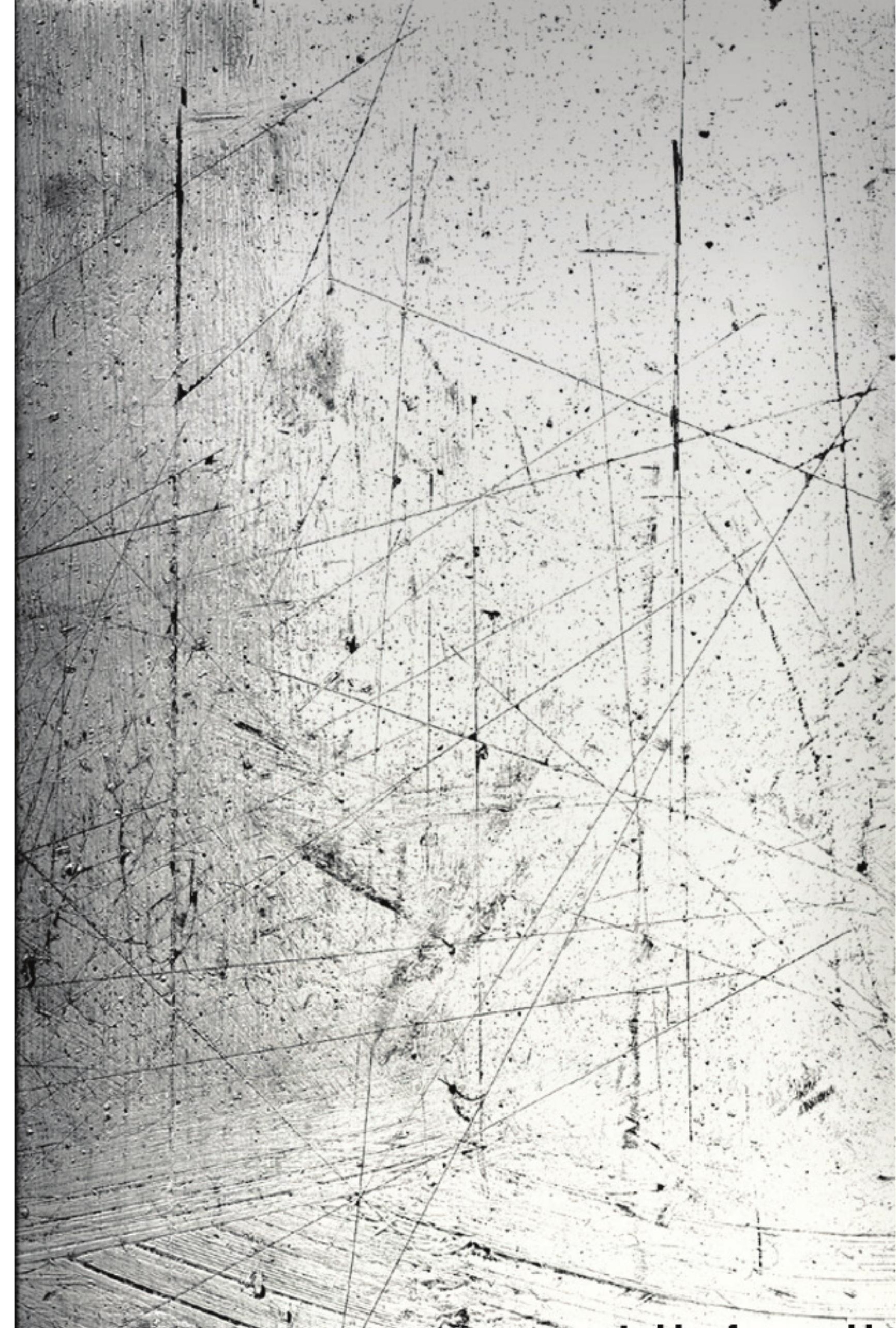

